\title{
Benefits of pre-loading temporary props for braced excavations
}

1 Benoît Latapie MSc, Eurlng

Technical Manager, Ground Engineering, WS Atkins \& Partners Overseas, Dubai, UAE (corresponding author: benoit.latapie@atkinsglobal.com; benoit.latapie@gmail.com)
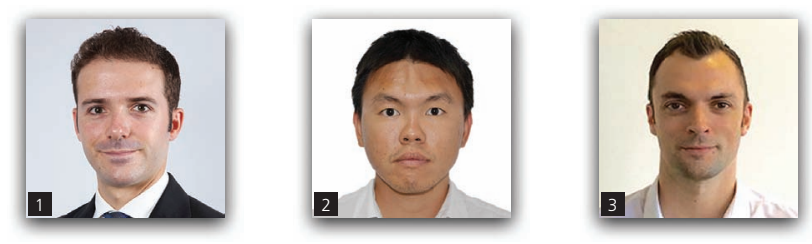

2 Terry Winarta MEng (Hons) Geotechnical Engineer, Ground Engineering, WS Atkins \& Partners Overseas, Dubai, UAE

3 Steven David Lloyd BSc (Hons) Development Manager, Groundforce Shorco, Leeds, UK

Using soil profiles typical of excavations in London, UK and Dubai, UAE calculations have been carried out to compare the performance of temporary steel and proprietary hydraulic propping. Numerical modelling indicates that pre-loading allows the lower-stiffness hydraulic prop to match the performance (in terms of prop load and wall displacement) of a higher-stiffness steel prop, without pre-load. The low prop stiffness also helps to mitigate loading induced by thermal effects. Furthermore, where limiting the horizontal deflection of the wall is critical, the application of a calibrated pre-load can improve the economy of the temporary works by reducing the prop size. Pre-loaded props are sometimes associated with increased bending moment and shear force values in the retaining wall. The finite-element models produced for this paper prove that for the cases considered, the use of pre-loaded low-stiffness hydraulic props achieved the same performance as stiff steel props, with no impact on the wall's reinforcement. Further work is suggested to explore how manipulating and varying the pre-loading values in multipropped basements might be used to improve further the performance and/or the economy of the retaining wall and how this might affect the load transfer from temporary to permanent supports in the longer term.

\section{Notation}

A cross-sectional area of a propping element

$A_{\text {hyd }} \quad$ cross-sectional area of hydraulic element of a proprietary prop

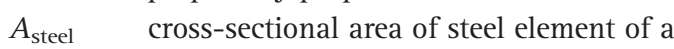
proprietary prop

$c^{\prime} \quad$ cohesion (drained)

$c_{\mathrm{u}} \quad$ undrained shear strength (cohesion)

$d \quad$ horizontal spacing distance of props

E Young's modulus of materials

EA axial stiffness

$E_{\text {concrete }}$ Young's modulus of concrete

$E_{\text {hyd }} \quad$ Young's modulus of hydraulic element of a proprietary prop

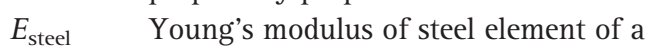
proprietary prop

$(E A)_{\text {wall }} \quad$ wall's axial stiffness

$(E I)_{\text {wall }} \quad$ wall's bending stiffness

$K_{\mathrm{o}} \quad$ coefficient of at-rest earth pressures

$L_{0} \quad$ initial length of a single prop

$L_{0, \text { hyd }} \quad$ initial length of hydraulic element of a proprietary prop

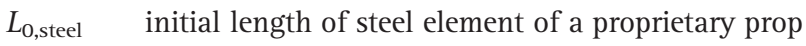

$P_{\text {hyd }} \quad$ working load of a hydraulic prop

\begin{tabular}{|c|c|}
\hline$P_{\text {pre-load }}$ & pre-load of a hydraulic prop \\
\hline$P_{\text {steel }}$ & working load of a steel prop \\
\hline$R_{\text {inter }}$ & strength reduction factor for soil-structure interface \\
\hline$S$ & $\begin{array}{l}\text { stiffness of a propping system expressed as stiffness } \\
\text { per unit length of wall: }(\mathrm{kN} / \mathrm{m}) / \mathrm{m}\end{array}$ \\
\hline$S_{0}$ & stiffness of a single prop: $\mathrm{kN} / \mathrm{m}$ \\
\hline$S_{n}$ & stiffness of element $n$ within a prop from 1 up to $N$ \\
\hline$t$ & wall's thickness \\
\hline$w_{\text {wall }}$ & wall's self-weight \\
\hline$Z_{\mathrm{LC}}$ & depth below the top of the London Clay \\
\hline$\alpha$ & $\begin{array}{l}\text { angle of prop axis away from the perpendicular to } \\
\text { the wall }\end{array}$ \\
\hline$\alpha_{\mathrm{t}}$ & coefficient of linear thermal expansion of steel prop \\
\hline$\beta$ & $\begin{array}{l}\text { empirical factor for percentage degree of restraint } \\
\text { against thermal strain }\end{array}$ \\
\hline$\gamma$ & unit weight of soil/rock materials \\
\hline$\gamma_{\text {sat }}$ & saturated unit weight of soil/rock materials \\
\hline$\Delta P_{\text {temp }}$ & change in axial prop load due to temperature change \\
\hline$\Delta t$ & change in prop temperature \\
\hline$\delta_{\text {pre-load }}$ & $\begin{array}{l}\text { positive value of the net horizontal deflection of the } \\
\text { retaining wall at the prop's location, induced by } \\
\text { applying } P_{\text {pre-load }}\end{array}$ \\
\hline$v$ & Poisson's ratio \\
\hline$\phi^{\prime}$ & angle of internal friction (drained) \\
\hline
\end{tabular}




\section{Introduction}

Shoring is a necessary part of almost every deep basement excavation where retention of soil materials and/or sustaining groundwater pressures is required. The most common construction method uses a 'bottom-up' technique, where the retaining wall is constructed initially and the excavation and installation of the support frames/props proceed downwards in stages. In this situation, the permanent works are constructed from the bottom of the supported excavation, working upwards. An alternative to this is a top-down construction method, which is not in the remit of this paper. The methods used vary greatly in terms of execution, but from a design point of view, they tend to follow a very similar pattern: an embedded retaining wall (e.g. diaphragm wall, secant/ contiguous bored pile wall, steel sheet piles) is supported by one or more levels of horizontal beam (e.g. concrete capping beam, steel waling beam), which is in turn supported by a series of props or anchors (e.g. raking props, flying shores, ground anchors). Shallow excavations, which are not in the remit of this paper, are sometimes retained with a retaining wall alone, acting as a cantilever.

In this paper, numerical modelling of deep propped excavations is used to investigate the potential benefits of pre-loading (or prestressing) the structural supports on the performance of the temporary work system. Different excavation depths and ground conditions are considered in order to ensure that the conclusions drawn in this paper are not reliant on conveniently chosen assumptions. Using past experience in both Dubai (UAE) and London (UK), representative temporary work scenarios were recreated and used in the analyses. The paper demonstrates that carefully selected values of pre-load may be used as substitutes for inherent prop stiffness. A discussion on the benefits of using props with lower stiffness, particularly with regard to dealing with the effect of temperature, is also included. Ground anchors and other support methods are not considered in this paper. Proprietary hydraulic props are used when analysing the scenarios where pre-load is introduced in the support system.

\section{A short history of hydraulic propping}

Proprietary hydraulic propping systems have been in use in the UK for well over 30 years. The benefits of using hydraulic rams to support relatively shallow excavations are widely accepted there, mostly from an ease of installation and practicality point of view. The use of this technique to support deep excavations has led to the development of high-load-capacity props over the last 10 years. The UK shoring industry has reached the point where proprietary rental equipment, for most temporary work applications, is a cost-effective alternative to traditional welded steel framework. In some cases - for example, deep complex cofferdam layouts where the ground and groundwater loads are very high - the traditional system remains the preferred (and only) option as the current range of proprietary rental equipment cannot accommodate such loads.

The modern proprietary hydraulic shoring props discussed in this paper include a hydraulic ram which is an integral part of the prop. The ram remains an active part of the prop throughout its service life. Figure 1 shows hydraulic props in service; the telescopic sleeves containing the hydraulic rams are labelled 'hydraulic unit'.

Previous literature has often focused on the effect of pre-loading of steel props. Construction Industry Research and Information Association report C517 by Twine and Roscoe (1999) lists a number of methods which may be used to introduce pre-load into a conventional steel prop. Such methods include driving wedges to secure the props or the waling (which introduces a small pre-load to the system) and using a removable jacking device between the steel prop and waling to push back the wall before installing the prop. Practical site experience shows that the use of such remote jacking systems requires additional installation time and in turn additional cost when compared to a modern proprietary hydraulic prop that has this facility built in. The control and monitoring of the pre-load value is also much easier and more precise when using the hydraulic system. Figure 2 shows the high-pressure couplings housed within the prop casing and the motorised pump that controls the flow of hydraulic fluid during the standard installation process. In this particular case, the corner prop shown was installed to the required position and pre-loaded in less than an hour.

Hydraulic actuation provides practical benefits during the installation process and facilitates greater control over any preloading that needs to be induced into the prop. However, using a hydraulic ram to support load results in a prop that is intrinsically less stiff when compared to a structurally equivalent steel prop. This is because the stiffness of a hydraulic prop is limited by the

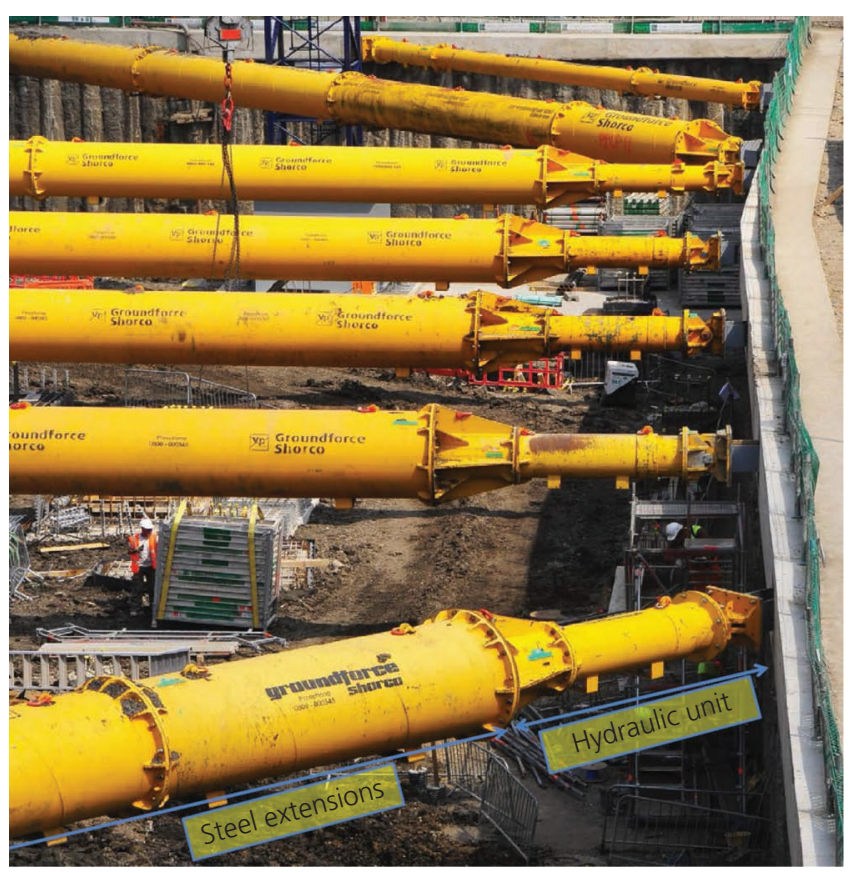

Figure 1. Proprietary hydraulic props in service 


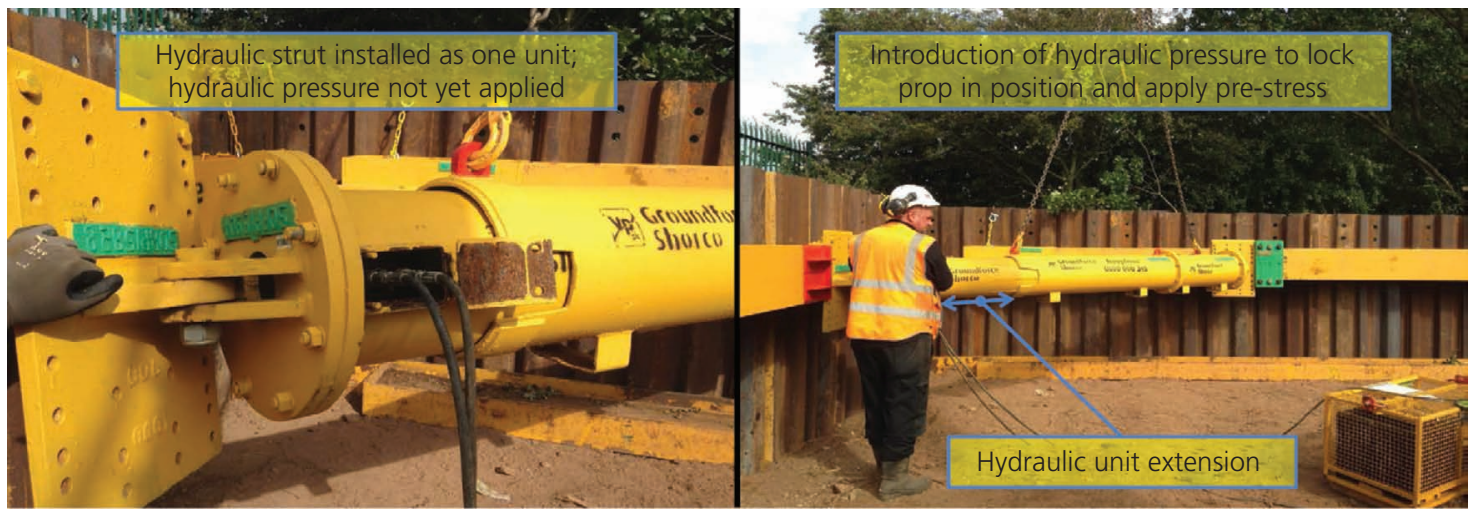

Figure 2. Proprietary hydraulic prop in service

stiffness of the column of fluid in compression within the ram itself. This is discussed in greater detail in the section headed 'Determination of the axial stiffness of hydraulic and nonhydraulic props'. Figure 3 shows the difference between a hydraulic prop and a conventional steel prop.

Irrespective of the prop type, all props used to support deep temporary excavations have two main properties that control their design: structural strength and stiffness. For a traditional steel prop, these two properties are directly related, as an increase in steel crosssection directly translates to a stronger and stiffer prop. This relationship is not as simple when considering hydraulic props as strength and stiffness are related to hydraulic ram properties as well as steel section properties. Hydraulic props are able to achieve a strength comparable to that of a conventional steel prop with a lower overall stiffness. This will be discussed in detail later in the paper.

Previous research by Chambers et al. (2016) showed that high prop pre-load values are not generally necessary to achieve satisfactory performance in terms of limiting wall movement. The research suggests that in the case of the Crossrail Paddington station box, a smaller (i.e. c. $30 \%$ of design load) pre-load would have offered satisfactory results with far greater economy compared to what was used in the construction. This paper

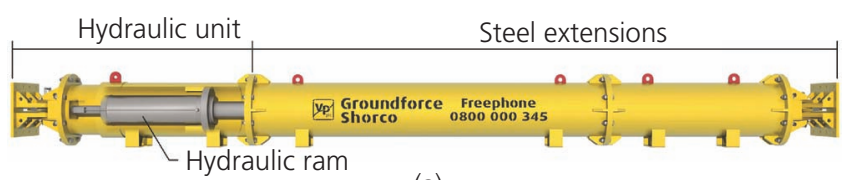

(a)

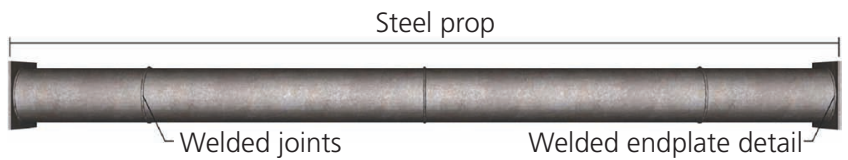

(b)

Figure 3. Comparison between (a) hydraulic prop and (b) typical steel prop expands on this research and demonstrates that pre-load used in combination with low-stiffness hydraulic props has a beneficial effect on the design of temporary retaining walls, in terms of both economy and performance.

\section{Ground model assumptions}

For the purpose of this paper, two different ground conditions have been adopted to explore the benefits of pre-loading temporary propping for deep-excavation works. Representative ground conditions (stratigraphy and ground parameters) for both London and Dubai were chosen by the authors due to their experience working on deep-excavation projects in these two cities. These ground conditions have been idealised to ease the comparison between the different excavation depths considered and are not meant to be directly applicable to any particular site. The assumptions and calculations presented in this paper should not be used in place of site-specific site investigation and project-specific design calculations.

The stratigraphy for typical ground condition in Dubai consists of cemented sand overlying a bedrock of highly weathered to moderately weathered calcarenite and calcisiltite. Many Dubai projects were constructed near its coastline where the groundwater level is relatively high, close to the existing ground level. In this paper, the groundwater level is assumed at $3 \mathrm{~m}$ below the existing ground level for the Dubai ground conditions. The corresponding ground model is illustrated in Figure 4.

The typical ground condition for the London model consists of made ground and river terrace deposits overlying the London Clay formation. The groundwater level is considered at $6 \mathrm{~m}$ below the ground level, which is the interface between the made ground and river terrace deposits. The corresponding ground model is illustrated in Figure 5.

The geotechnical parameters assumed for both ground conditions are summarised in Table 1. These parameters were selected after reviewing several factual site investigation reports for Dubai and London projects. The authors' intention is to analyse a set of typical or representative parameters for each location. 
Geotechnical Research

Volume 4 Issue GR3
Benefits of pre-loading temporary props

for braced excavations

Latapie, Winarta and Lloyd

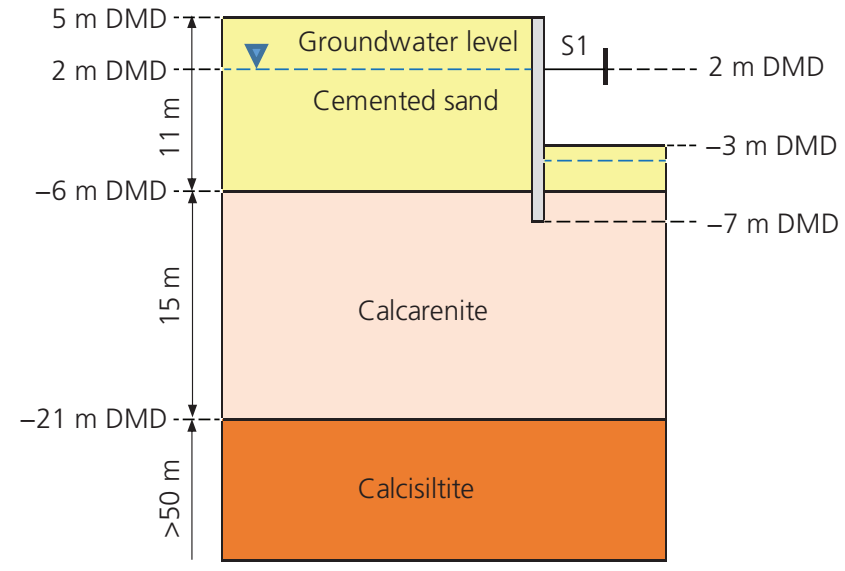

(a)

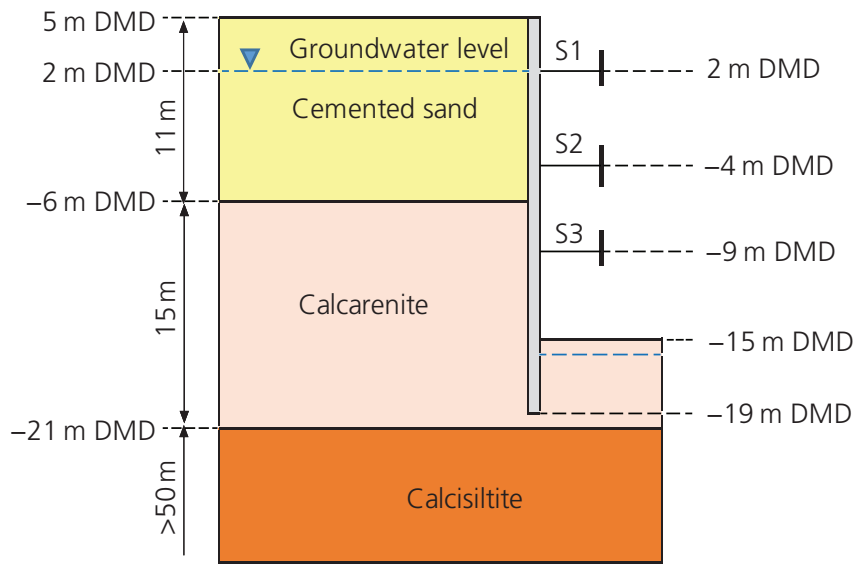

(b)

Figure 4. Stratigraphy and analysed model for Dubai: (a) propped cantilever - Dubai (PCD) and (b) multipropped - Dubai (MPD). DMD, Dubai Municipality Datum

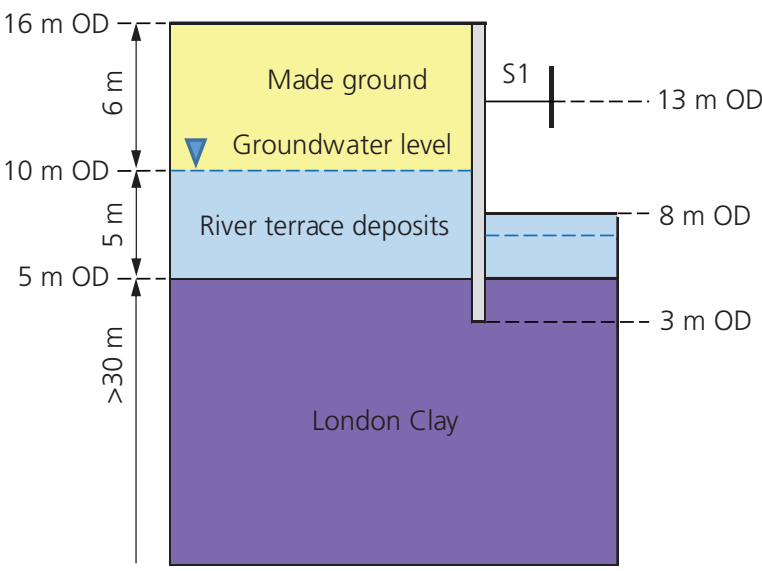

(a)

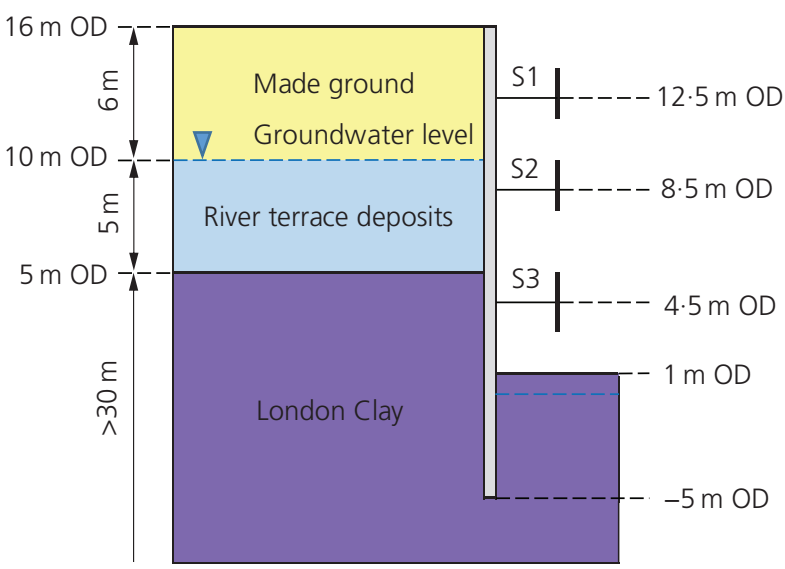

(b)

Figure 5. Stratigraphy and analysed model for London: (a) propped cantilever - London (PCL) and (b) multipropped - London (MPL). OD, Ordnance Datum

Table 1. Characteristic geotechnical parameters of soil/rock materials

\begin{tabular}{|c|c|c|c|c|c|c|c|}
\hline Lithology & $\gamma: \mathrm{kN} / \mathrm{m}^{3}$ & $c^{\prime}: \mathrm{kPa}$ & $c_{\mathrm{u}}: \mathrm{kPa}$ & $\phi^{\prime}: \circ$ & E: MPa & $v$ & $\kappa_{\mathrm{o}}$ \\
\hline \multicolumn{8}{|c|}{ Dubai } \\
\hline Cemented sand & 19 & 2 & - & 32 & 50 & $0 \cdot 30$ & 0.47 \\
\hline Calcarenite & 21 & 125 & - & 40 & 200 & 0.25 & 0.36 \\
\hline Calcisiltite & 21 & 300 & - & 30 & 750 & 0.25 & $0 \cdot 50$ \\
\hline \multicolumn{8}{|c|}{ London } \\
\hline Made ground & 20 & 0 & - & 32 & 12 & 0.25 & 0.61 \\
\hline River terrace deposits & 20 & 0 & - & 36 & 100 & $0 \cdot 15$ & 0.41 \\
\hline London Clay & 20 & - & $100+5 \cdot 34 z_{L} C^{a}$ & - & $80+4 \cdot 27 Z_{L C}{ }^{a}$ & 0.495 & 1.00 \\
\hline
\end{tabular}

a These equations highlight the fact that undrained shear strength and stiffness for the London Clay vary with depth, where $z$ is the depth below the top of the London Clay. They were obtained from a specific past project experience in London, where the values are derived from standard penetration test correlations and triaxial test results 


\section{Geotechnical modelling}

To predict the relationship between shoring stiffness and excavation-induced loads and displacements, the authors have chosen to use the finite-element software Plaxis 2D to carry out the numerical modelling required to support this paper.

To facilitate the comparison between models and the interpretation of the results, the authors have tried to keep the analysis as straightforward as possible. A set of assumptions common to all models was defined to ease comparisons of results and enable drawing meaningful conclusions from their interpretation. The assumptions and general conditions made in the model are the following.

- The retaining wall was chosen as an $800 \mathrm{~mm}$ thick diaphragm wall, with the properties presented in Table 2 .

- The elasto-plastic Mohr-Coulomb constitutive model was used for the soil and rock materials.

- All the ground materials are considered as drained apart from London Clay, which was assumed to be undrained. This choice was made in the context of the short-term construction displacements estimated in the models.

- The models were analysed using a two-dimensional plane strain symmetry.

- All analyses were carried out with unfactored geotechnical parameters to obtain models that behave closely to real situations. Where required, partial factors were applied to the analyses' output in order to obtain ultimate limit state values and support the structural calculations.

- The shoring systems presented in this paper were analysed to resist full hydrostatic pressure without the benefit of pore water pressure redistribution caused by dewatering.

- The staged construction sequence was modelled to match realistic site conditions - namely, the following.

- The groundwater level inside the excavation was set to be $1 \mathrm{~m}$ below the formation level for every intermediate construction stage.

- A height of $1.0 \mathrm{~m}$ for the working space was left below each prop centre line, before their 'installation' in the models.

- Construction surcharges were modelled as uniformly distributed, with a magnitude of $20 \mathrm{kPa}$, acting at ground level with a $1 \mathrm{~m}$ offset from the edge of excavation.

- A reduced friction was assumed at the interface between the retaining wall and the ground behind it to account for

Table 2. Summary of diaphragm wall parameters

$\begin{array}{lccc}\text { Parameter } & \text { Symbol } & \text { Unit } & \text { Value } \\ \text { Wall thickness } & t & \mathrm{~mm} & 800 \\ \text { Young's modulus } & E_{\text {concrete }} & \mathrm{GPa} & 32 \\ \text { Axial stiffness } & (E A)_{\text {wall }} & \mathrm{kN} / \mathrm{m} & 25.6 \times 10^{6} \\ \text { Bending stiffness } & (E /)_{\text {wall }} & \left(\mathrm{kN} / \mathrm{m}^{2}\right) / \mathrm{m} & 955.7 \times 10^{3} \\ \text { Self-weight } & \text { Wwall }_{\text {wall }} & (\mathrm{kN} / \mathrm{m}) / \mathrm{m} & 19.2\end{array}$

construction effects. To model this in Plaxis 2D, an $R_{\text {inter }}$ parameter of 0.7 was taken. This corresponds to a $30 \%$ reduction in shear strength at the interface to take into account the impact of the construction methodology of the diaphragm wall onto the concrete-ground interface friction. This is in line with the values recommended by Gaba et al. (2003).

The characteristic geotechnical parameters for the soil/rock materials are presented in Table 1.

\section{Excavation models}

For each of the two different ground conditions considered, two excavation depths were analysed to represent a range of typical temporary work scenarios encountered in the industry. This gave a total of four models, for all of which an excavation footprint of $30 \mathrm{~m}$ width by $60 \mathrm{~m}$ length was assumed. The first geometry corresponds to (relatively shallow) excavation works for the construction of a single basement level, with a final formation level located $8 \mathrm{~m}$ below ground level. A propped cantilever wall was used in this case. The second situation represents the deepexcavation works required to construct multiple basement levels, with a final formation level located at 15 and $20 \mathrm{~m}$ below ground level for London and Dubai ground conditions, respectively. For these deep excavations, three levels of propping were adopted.

A diaphragm wall was adopted for all cases, with the parameters presented in Table 2. In accordance with Gaba et al. (2003), the bending stiffness for the diaphragm wall is reduced to $70 \%$ of its theoretical value to take into account the crack width that developed during the relatively short construction period. For the temporary props, circular hollow section (CHS) steel members were adopted for the analyses, comparing typical steel sections against hydraulic proprietary props. The different models were computed iteratively, varying the prop type, spacing and pre-load levels or, in other words, altering the prop's stiffness value (per m run of model) until the target deflection criterion was met. This is discussed in detail in the methodology.

The position of props supporting the wall and the required wall embedment depth to achieve sufficient stability were pre-determined by way of hand calculations, before running the finite-element models. The hand calculations were carried out following Rankine's earth pressure theory to pre-determine the earth pressures acting on the retaining wall and in accordance with the methods proposed by Burland et al. (1981) to calculate the overall stability of the walls against overturning. Both prop levels and toe embedment were subsequently refined and optimised iteratively in the finite-element model to ensure a reasonable distribution of bending moments and shear forces throughout the depth of the wall while maintaining a buildable prop layout. Figures 4 and 5 illustrate the scenarios analysed for Dubai and London, respectively. In each case, a propped cantilever and a multipropped geometry are presented.

The construction sequence stages for these models are provided in Table 3. 
Table 3. Construction sequence stages

\begin{tabular}{|c|c|c|c|c|}
\hline Model/stage & PCD & PCL & MPD & MPL \\
\hline 1 & Excavate to $+3 \mathrm{~m}$ DMD & Excavate to $+14 \mathrm{~m}$ OD & Excavate to $+3 \mathrm{~m} \mathrm{DMD}$ & Excavate to $+14 \mathrm{~m}$ OD \\
\hline 2 & $\begin{array}{l}\text { Excavate to } 1 \mathrm{~m} \text { below } \mathrm{S} 1 \\
\text { at }+1 \mathrm{~m} \mathrm{DMD}\end{array}$ & $\begin{array}{l}\text { Excavate to } 1 \mathrm{~m} \text { below } \mathrm{S} 1 \\
\text { at }+12 \mathrm{~m} \text { OD }\end{array}$ & $\begin{array}{l}\text { Excavate to } 1 \mathrm{~m} \text { below } \mathrm{S} 1 \\
\text { at }+1 \mathrm{~m} \text { DMD }\end{array}$ & $\begin{array}{l}\text { Excavate to } 1 \mathrm{~m} \text { below } \mathrm{S} 1 \\
\text { at }+11.5 \mathrm{~m} \mathrm{OD}\end{array}$ \\
\hline 3 & Install S1 at $+2 \mathrm{~m} \mathrm{DMD}$ & Install S1 at $+13 \mathrm{~m}$ OD & Install S1 at +2 m DMD & Install S1 at $+12 \cdot 5 \mathrm{~m} \mathrm{OD}$ \\
\hline 4 & Excavate to $-1 \mathrm{~m}$ DMD & Excavate to $+10 \mathrm{~m}$ OD & Excavate to $-2 \mathrm{~m}$ DMD & Excavate to $+10 \mathrm{~m}$ OD \\
\hline 5 & Excavate to FEL at $-3 \mathrm{~m}$ DMD & Excavate to FEL at $+8 \mathrm{~m}$ OD & $\begin{array}{l}\text { Excavate to } 1 \mathrm{~m} \text { below } \mathrm{S} 2 \\
\text { at }-5 \mathrm{~m} \text { DMD }\end{array}$ & $\begin{array}{l}\text { Excavate to } 1 \mathrm{~m} \text { below } \mathrm{S} 2 \\
\text { at }+7.5 \mathrm{~m} \mathrm{OD}\end{array}$ \\
\hline 6 & - & - & Install S2 at $-4 \mathrm{~m}$ DMD & Install S2 at $+8 \cdot 5 \mathrm{~m}$ OD \\
\hline 7 & - & - & Excavate to $-8 \mathrm{~m}$ DMD & $\begin{array}{l}\text { Excavate to } 1 \mathrm{~m} \text { below } \mathrm{S} 3 \\
\text { at }+3.5 \mathrm{~m} \text { OD }\end{array}$ \\
\hline 8 & - & - & $\begin{array}{l}\text { Excavate to } 1 \mathrm{~m} \text { below } \mathrm{S} 3 \\
\text { at }-10 \mathrm{~m} \mathrm{DMD}\end{array}$ & Install S3 at $+4.5 \mathrm{~m} \mathrm{OD}$ \\
\hline 9 & - & - & Install S3 at -9 m DMD & Excavate to FEL at $+1 \mathrm{~m} \mathrm{OD}$ \\
\hline 10 & - & - & Excavate to FEL at $-15 \mathrm{~m}$ DMD & - \\
\hline
\end{tabular}

FEL, final excavation level

\section{Methodology}

In accordance with most international standards, the design of structural members supporting temporary excavations needs to include at least two verifications: serviceability and ultimate limit states. Those two limit states are commonly translated to an allowable deflection and structural capacity, respectively. It is quite common for temporary works, particularly in urban environments, to be designed to achieve a specified performance criterion or, in other words, not to exceed the maximum allowable wall deflection. This is to minimise the ground-movementinduced damage to existing structures and services adjacent to the site. The criteria used in this paper were set to follow the same philosophy where the maximum wall deflections were limited to 30 and $15 \mathrm{~mm}$ for the Dubai and London models, respectively. These criteria are based on the authors' experience working in both cities. The limit for London is more stringent, mainly because the city is more congested than Dubai and the majority of its existing infrastructure is very sensitive to ground movements.

Using the deflection criterion defined earlier, a staged analysis was carried out for all four models, using conventional steel propping and then pre-loaded hydraulic props to achieve the same performance criteria (i.e. the same maximum wall deflection). The determination of the structural resistance of the selected props is discussed in detail in the next section.

First, the model was analysed with conventional non-pre-loaded CHS steel props, installed at a horizontal spacing chosen to achieve the specified performance criteria. The size of the CHS member and its spacing was selected based on the governing factor of either the structural capacity of the member or the deflection limit set for the retaining wall. Subsequently, the same model was analysed with hydraulic props using their nominal pre-load. This usually leads to a higher wall deflection than the first analysis, due to the lower stiffness of the props and the small amount of pre-load. An iterative procedure followed where calibrated pre-load values were adjusted and set to meet the same performance criteria as the conventional non-pre-loaded CHS steel props. The horizontal spacings of the props in all the analyses were kept identical so that the output data from the numerical analyses are directly comparable.

A flow chart depicting the analysis is shown in Figure 6.

\section{Determination of the structural resistance of tubular hydraulic and non-hydraulic props}

Determination of the structural resistance to the axial loading of the non-hydraulic steel CHS props was carried out by standard methodology in accordance with BS EN 1993-1-1:2005 (BSI, 2005 ) and in the case of class 4 (slender) sections by using the approach outlined by Groundforce Shorco (2015).

The resistance of a hydraulic prop was calculated as being the lesser of $(a)$ its hydraulic components and $(b)$ its resistance to buckling as governed by the constituent CHS section capacity. Typically, it is the hydraulic ram capacity that limits overall axial resistance on short to medium prop lengths and resistance to buckling dictates thereafter. This transition is illustrated in the typical prop resistance chart shown in Figure 7.

The axial capacities of the conventional steel tubes and the proprietary hydraulic props used in this paper, for a $30 \mathrm{~m}$ wide excavation, are summarised in Table 4. Where buckling is the governing factor, steel and hydraulic props that use an identical CHS section have the same structural capacity. The resistance of a hydraulic ram is calculated based on its cylindrical diameter, length, wall thickness and material, as well as the pressure rating of seals, fixtures and other components. Once the theoretical resistance has been estimated, it is then verified by factory testing before a final value is allocated to a specific ram 
Benefits of pre-loading temporary props

for braced excavations

Latapie, Winarta and Lloyd

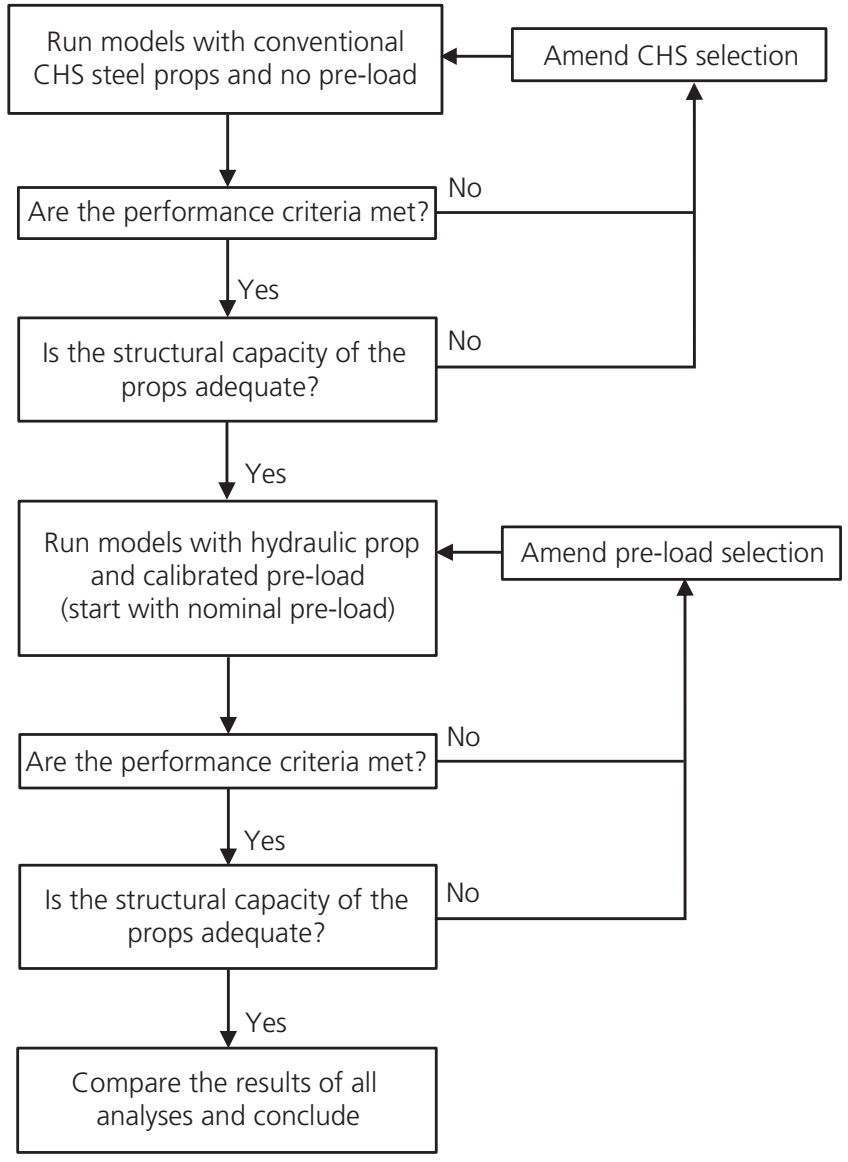

Figure 6. Flow chart depicting the numerical modelling analyses

and the hydraulic prop is produced. The resistance of hydraulic rams is independent of the prop length.

\section{Determination of the axial stiffness of hydraulic and non-hydraulic props}

Equation 1 is derived from Hooke's law and calculates the axial stiffness of a propping system per unit length of wall, comprising multiple struts of initial length $L_{0}$ acting at an angle $\alpha$ from the normal of the plane of the wall and installed at a lateral spacing, $d$

1. $S=\frac{E A\left(\cos ^{2} \alpha\right)}{L_{0} d}$

Note: $(a) \alpha=0^{\circ}$ for props perpendicular to the supporting wall; therefore, $\cos ^{2} \alpha=1$. (b) The effect on overall system stiffness due to the flexural stiffness of the supported elements (e.g. diaphragm walls, capping or intermediate waling beams) is not accounted for in Equation 1. It is the authors' experience that the flexural stiffness of the wall is generally ignored as it does not have a significant effect on the results.

Table 4. Typical characteristic geotechnical force on prop type

\begin{tabular}{|lcc|} 
Prop type Diameter $\times$ wall thickness & $\begin{array}{c}\text { Characteristic } \\
\text { geotechnical force, } \\
\text { applied axially, } \\
\text { which will give rise to } \\
\mathbf{1 0 0 \%} \text { structural } \\
\text { utilisation: } \mathbf{k N}\end{array}$ \\
\hline Steel CHS & $711 \times 12.5 \mathrm{~mm}$ & 1308 \\
& $813 \times 14.2 \mathrm{~mm}$ & 2102 \\
Hydraulic & $1016 \times 12.5 \mathrm{~mm}$ & 2541 \\
& $1016 \times 14.2 \mathrm{~mm}$ & 3141 \\
& Groundforce MP150 & 7174 \\
& Groundforce MP250 & 1748 \\
Groundforce MP450 & 2503 \\
\hline
\end{tabular}

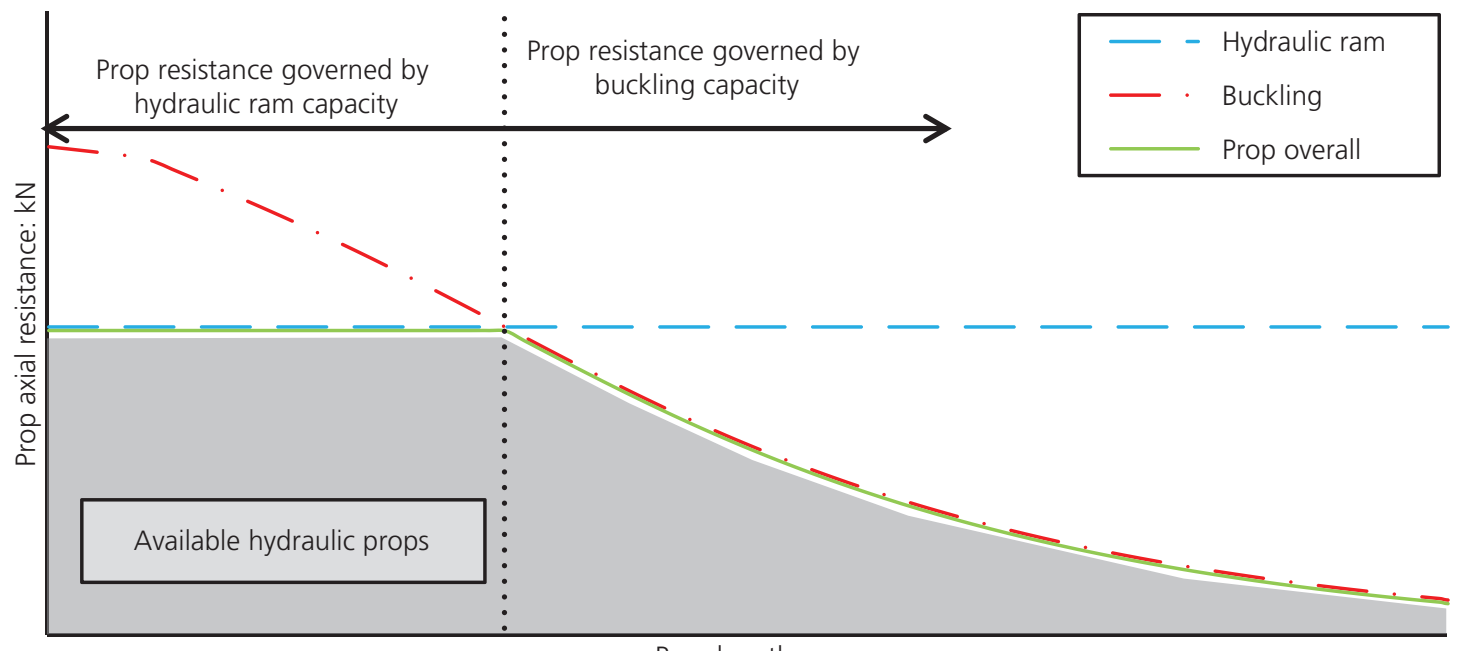

Prop length: $m$

Figure 7. Typical prop resistance 
Benefits of pre-loading temporary props

for braced excavations

Latapie, Winarta and Lloyd
The axial stiffness of a single prop is calculated by using the equation

$$
\text { 2. } S_{0}=\frac{E A}{L_{0}}
$$

Equation 1 is valid for a steel prop modelled as a uniform element. This equation is used to determine the stiffness of the steel CHS props used in this paper. However, proprietary hydraulic props, as shown in Figure 3, consist of two elements, each of different axial stiffness. To take this factor into account, the following approach is adopted in order to calculate the overall axial stiffness of these prop types.

Equation 3 is also derived from Hooke's law and states that for elements connected end to end (in series), the reciprocal of the resultant stiffness is the sum of the reciprocals of all of the connecting elements that make up the series

3. $\frac{1}{S_{0}}=\frac{1}{S_{1}}+\frac{1}{S_{2}}+\cdots+\frac{1}{S_{N}}$

The stiffness of each individual element can be calculated from Equation 2 by using appropriate parameters and substituted into
Equation 3 to determine the resultant stiffness of the composite hydraulic prop as shown in the equation

4. $\quad S_{0}=\frac{1}{\left(L_{0, \text { hyd }} / E_{\text {hyd }} A_{\text {hyd }}\right)+\left(L_{0, \text { steel }} / E_{\text {steel }} A_{\text {steel }}\right)}$

By substituting this combined stiffness value $S_{0}$ back into Equation 1, the stiffness (per metre run) of a series of hydraulic props installed at spacing $d$ can be calculated from the equation

5. $S=\frac{S_{0}}{d}$

The parameters of length, area and Young's modulus for the hydraulic ram elements of the proprietary props used in this paper are stated in Table 5. An appropriate specification of hydraulic ram is selected to meet the strength requirements stated in Table 4.

It is the length of the column of hydraulic fluid within the ram, after the strut has been pumped out during the installation process, that is used to calculate axial stiffness. For example, an MP250 prop installed at nominal $30 \mathrm{~m}$ length requires the hydraulic ram to be pumped out by $0.9 \mathrm{~m}$. The calculated prop stiffness values are summarised in Table 7.

Table 5. Characteristics of hydraulic ram

\begin{tabular}{|c|c|c|c|c|c|c|c|c|}
\hline $\begin{array}{l}\text { Prop } \\
\text { type }\end{array}$ & $\begin{array}{c}\text { Hydraulic ram } \\
\text { type }\end{array}$ & $\begin{array}{c}\text { Full bore } \\
\text { area: } \\
\mathrm{mm}^{2}\end{array}$ & $\begin{array}{l}\text { Young's } \\
\text { modulus: } \\
\text { N/mm² }\end{array}$ & $\begin{array}{c}\text { Max stroke of } \\
\text { hydraulic ram: } \\
\text { mm }\end{array}$ & $\begin{array}{c}\text { Ram } \\
\text { housing } \\
\text { length: } \mathrm{mm}\end{array}$ & $\begin{array}{l}\text { Nominal } \\
\text { minimum pre- } \\
\text { load: kN }\end{array}$ & $\begin{array}{c}\text { Standard } \\
\text { achievable pre- } \\
\text { load: kN }\end{array}$ & $\begin{array}{c}\text { Maximum } \\
\text { achievable pre- } \\
\text { load: kN }\end{array}$ \\
\hline $\mathrm{C}_{\text {Hyd }}$ & Groundforce MP150 & 31416 & 1600 & 1150 & 3550 & 325 & 866 & 1748 \\
\hline $\begin{array}{l}A_{\text {Hyd }} \\
B_{\text {Hyd }} \\
D_{\text {Hyd }}\end{array}$ & Groundforce MP250 & 49087 & 1600 & 1066 & 3100 & 505 & 1355 & 2503 \\
\hline $\mathrm{E}_{\mathrm{Hyd}}$ & Groundforce MP450 & 96212 & 1600 & 1050 & 3100 & 910 & 2435 & 4505 \\
\hline
\end{tabular}

Table 6. Summary of the temporary prop types used in the analysis

\begin{tabular}{|c|c|c|c|c|}
\hline Prop type & CHS member & Spacing: $m$ & $\begin{array}{l}\text { Maximum characteristic axial } \\
\text { force per metre: } \mathrm{kN} / \mathrm{m}\end{array}$ & $\begin{array}{l}\text { Strut stiffness: } \\
\text { kN/m }\end{array}$ \\
\hline A & CHS $1016 \times 12.5 \mathrm{~mm}$ & 12 & 212 & 689700 \\
\hline$A_{\text {Hyd }}$ & CHS $1016 \times 12.5 \mathrm{~mm}$ c/WMP250 hydraulic ram unit & 12 & 209 & 166935 \\
\hline $\mathrm{B}$ & CHS $813 \times 14.2 \mathrm{~mm}$ & 12 & 175 & 623550 \\
\hline $\mathrm{B}_{\text {Hyd }}$ & CHS $813 \times 14.2 \mathrm{~mm}$ c/W MP250 hydraulic ram unit & 12 & 175 & 162885 \\
\hline C & CHS $711 \times 12.5 \mathrm{~mm}$ & 5 & 262 & 1152000 \\
\hline $\mathrm{C}_{\text {Hyd }}$ & CHS $711 \times 12.5 \mathrm{~mm} \mathrm{c} / \mathrm{w}$ MP150 hydraulic ram unit & 5 & 262 & 250590 \\
\hline D & CHS $1016 \times 12.5 \mathrm{~mm}$ & 5 & 508 & 1655100 \\
\hline$D_{\text {Hyd }}$ & CHS $1016 \times 12.5 \mathrm{~mm} \mathrm{c} / \mathrm{W}$ MP250 hydraulic ram unit & 5 & 501 & 400650 \\
\hline E & CHS $1016 \times 14.2 \mathrm{~mm}$ & 5 & 628 & 1876950 \\
\hline $\mathrm{E}_{\mathrm{Hyd}}$ & CHS $1016 \times 14.2 \mathrm{~mm}$ c/w MP450 hydraulic ram unit & 5 & 628 & 670605 \\
\hline $\mathrm{F}$ & CHS $1220 \times 20 \mathrm{~mm}$ & 5 & 1435 & 3166800 \\
\hline G & CHS $1220 \times 20 \mathrm{~mm}$ & 2 & 3587 & 7916850 \\
\hline $\mathrm{H}$ & CHS $1220 \times 20 \mathrm{~mm}$ & 3 & 2391 & 5277900 \\
\hline
\end{tabular}

c/w, combined with 
Table 7. Summary of results for PCD, PCL and MPD

\begin{tabular}{|c|c|c|c|c|c|c|}
\hline Analysis & $\begin{array}{l}\text { Prop } \\
\text { level }\end{array}$ & $\begin{array}{l}\text { Prop } \\
\text { type }\end{array}$ & $\begin{array}{l}\text { Working load } \\
\text { output: kN/m } \\
\text { [utilisation: \%] }\end{array}$ & $\begin{array}{c}\text { Pre-load applied as a percentage of the } \\
\text { working load: } \%\end{array}$ & $\begin{array}{l}\text { Strut stiffness: } \\
\mathrm{kN} / \mathrm{m}\end{array}$ & $\begin{array}{l}\text { Maximum wall } \\
\text { deflection: } \mathrm{mm}\end{array}$ \\
\hline PCD & S1 & A & 203 [97] & N/A & 689700 & 14 \\
\hline PCD & S1 & $A_{\text {Hyd }}$ & 198 [95] & 57 & 166935 & 14 \\
\hline $\mathrm{PCL}$ & S1 & B & 164 [94] & N/A & 623550 & 10 \\
\hline$P C L$ & S1 & $\mathrm{B}_{\mathrm{Hyd}}$ & 163 [93] & 49 & 162885 & 10 \\
\hline MPD & S1 & C & 257 [98] & N/A & 1152000 & 15 \\
\hline MPD & S1 & $\mathrm{C}_{\text {Hyd }}$ & 242 [93] & 58 & 250590 & 15 \\
\hline MPD & S2 & D & 475 [93] & $\mathrm{N} / \mathrm{A}$ & 1655100 & 15 \\
\hline MPD & S2 & $D_{\text {Hyd }}$ & 458 [91] & 59 & 400650 & 15 \\
\hline MPD & S3 & $\mathrm{E}$ & 626 [99] & $\mathrm{N} / \mathrm{A}$ & 1876950 & 15 \\
\hline MPD & S3 & $E_{H y d}$ & 628 [99] & 48 & 670605 & 15 \\
\hline
\end{tabular}

N/A, not applicable

\section{Summary of props used in the analysis}

Based on the methodology flow chart presented in Figure 6, the authors have selected suitable temporary props and the typical spacing required to satisfy both the deflection limit of the wall and the structural capacity of the prop, which are presented in Table 6. The maximum characteristic axial resistance values stated are based on either the structural capacity of the steel prop or the capacity of the hydraulic unit. Steel props are denoted with a capital letter (i.e. A), and hydraulic props are denoted as $\mathrm{A}_{\mathrm{Hyd}}$.

\section{Values of nominal pre-load and achievable pre-load}

Two types of props were proposed for investigation in this paper, namely

- conventional steel props

- hydraulic props with calibrated pre-load to achieve the performance of conventional steel prop in terms of wall deflections.

The values for nominal minimum and maximum achievable preloads are outlined in Table 5 for each prop type used. Standard achievable values of pre-loads may be reached with standard hydraulic pumping equipment able to apply 4000 pounds per square inch (psi) (25.6 MPa). The hydraulic ram can, however, be pre-loaded up to its capacity (or maximum achievable pre-load) by using special hydraulic equipment tailored to the target preload and able to apply sufficiently high pressures.

\section{Results}

The analyses have shown that the design of the temporary props is governed either by the structural capacity of the prop (for the PCD, PCL and MPD cases), as presented in Table 7, or the deflection limit of the retaining wall (MPL case), as presented in Table 8.

The output working loads for the steel and hydraulic prop of the same model at the same level are very similar, with no more than $6 \%$ difference. The analysis results presented in Table 7 show that all temporary props (steel and hydraulic) are highly utilised (over $90 \%$ utilisation ratio) with wall deflections well below the limiting criteria. This means that the choice of the props for these scenarios is governed by the structural (buckling) capacity of the steel section, which does not enable material savings when replacing the conventional steel props with the proprietary hydraulic props.

The axial stiffness of the conventional steel props was reduced by 64 and 78\% for MPD prop levels S3 and S1, respectively, when replaced with hydraulic props. This is due to the incorporation of the hydraulic unit within the prop assembly, which has a lower stiffness than the equivalent length of CHS. The benefit of reduction in prop stiffness in the context of temperature effects is further discussed in the section headed 'Benefit of lower prop stiffness for thermal effects'.

The results in Table 7 confirm that the performance (i.e. maximum wall deflection) of conventional steel props can be replicated with the use of hydraulic props with calibrated pre-

Table 8. MPL - comparison between cases for wall deflection and working load

\begin{tabular}{|c|c|c|c|c|c|}
\hline $\begin{array}{l}\text { Prop } \\
\text { level }\end{array}$ & $\begin{array}{l}\text { Prop } \\
\text { type }\end{array}$ & $\begin{array}{l}\text { Working load } \\
\text { output: kN/m } \\
\text { [utilisation: \%] }\end{array}$ & $\begin{array}{l}\text { Pre-load applied as a percentage of the } \\
\text { working load: } \%\end{array}$ & $\begin{array}{l}\text { Strut stiffness: } \\
\text { kN/m }\end{array}$ & $\begin{array}{l}\text { Maximum wall } \\
\text { deflection: } \mathrm{mm}\end{array}$ \\
\hline S1 & $\mathrm{F}$ & 190 [13] & N/A & 3166800 & 15 \\
\hline $\mathrm{S} 2$ & G & $500[14]$ & N/A & 7916850 & 15 \\
\hline S3 & $\mathrm{H}$ & $421[18]$ & N/A & 5277900 & 15 \\
\hline S1 & $\mathrm{C}_{\text {Hyd }}$ & 199 [76] & 60 & 250590 & 15 \\
\hline S2 & $D_{\text {Hyd }}$ & 460 [91] & 74 & 400650 & 15 \\
\hline S3 & $D_{\text {Hyd }}$ & 426 [85] & 75 & 400650 & 15 \\
\hline
\end{tabular}

N/A, not applicable 
loads. This proves that the application of a pre-load enables a lower-stiffness proprietary hydraulic prop to match the performance (or stiffness) of a conventional high-stiffness steel prop. This principle is illustrated by the equation

6. $\frac{P_{\text {steel }} \times L_{0}}{E_{\text {steel }} \times A_{\text {steel }}}=\frac{\left(P_{\text {hyd }}-P_{\text {pre-load }}\right)}{S_{0}}-\delta_{\text {pre-load }}$

$P_{\text {steel }}$ and $P_{\text {hyd }}$ are the working loads for the conventional steel and hydraulic props, respectively. These are almost identical for the cases analysed and presented in this paper. $P_{\text {pre-load }}$ is the preload applied to the proprietary hydraulic prop and $\delta_{\text {pre-load }}$ is the positive value of the net horizontal deflection of the retaining wall, towards the retained side and at the prop's location, induced by applying $P_{\text {pre-load. }}$ After interrogating the analyses outputs, a range of $2 \cdot 3-4 \cdot 5 \mathrm{~mm}$ was found for $\delta_{\text {pre-load. }}$ Its value is normally higher for the top prop and reduces for deeper prop levels. This is because this parameter depends on the combined stiffness of the retaining wall and the ground behind it in response to the applied pre-load. One may calculate $P_{\text {pre-load }}$ by using Equation 6 with these approximate values of $\delta_{\text {pre-load }}$ to obtain an initial estimate and accelerate the design procedure.

The authors' analyses have found that the pre-load required to match the performance of the conventional steel prop ranges between 48 and $59 \%$ of the prop's working load, which are within the standard achievable pre-load defined in Table 5.

The results of the authors' analyses of the temporary props in multipropped 'London ground conditions' showed that their design is governed by the $15 \mathrm{~mm}$ deflection limit of the retaining wall rather than their structural capacity. For the purpose of the paper, a very narrow prop spacing was introduced for conventional steel prop analysis for S2 and S3 (CHS $1220 \times 20 \mathrm{~mm}$ with 2 and $3 \mathrm{~m}$ spacings, respectively) to satisfy the deflection limit. As summarised in Table 8 , the results of this analysis indicate very low utilisation ratios, between 13 and $18 \%$. This means that choosing conventional steel props in such a situation would lead to inefficient and possibly uneconomical design.

In contrast, in the analysis of hydraulic props under the same ground conditions, a typical spacing of $5 \mathrm{~m}$ was used as less prop stiffness was required to achieve the deflection criterion. Instead, pre-loads were introduced to all three levels of the proprietary hydraulic prop to satisfy the $15 \mathrm{~mm}$ limit criterion. Prop sizes were reduced to CHS $711 \times 12.5 \mathrm{~mm}$ combined with a MP150 hydraulic unit for the $\mathrm{S} 1$ level and CHS $1016 \times 12.5 \mathrm{~mm}$ combined with a MP250 hydraulic unit for the S2 and S3 levels. In comparison with the conventional steel prop, the utilisation ratio of the structural capacity was increased to between 76 and $91 \%$. This result indicates that the hydraulic proprietary props are working more efficiently compared to the conventional steel prop. As shown in Table 9, the use of hydraulic props for the MPL case enabled nearly $74 \%$ savings in steel quantities.

As presented in Table 9, in the MPL case, the axial stiffness of the conventional steel props was reduced by $92 \%$ (prop levels S1 and S3) to $95 \%$ (prop level S2) when replaced with hydraulic props, which is due to the incorporation of the hydraulic unit within the prop assembly.

In Table 8, the pre-load applied to $\mathrm{D}_{\mathrm{Hyd}}$ (for S2 and S3) exceeds the standard achievable pre-load (see Table 5). The pre-load values presented may be achieved by using specialist pumping equipment with hydraulic pressure capacity of $5000 \mathrm{psi}$ $(34.5 \mathrm{MPa})$, which is within the maximum achievable pre-load of the hydraulic ram.

The reduction in prop sizes, combined with increased spacing, indicates a greater efficiency, and economic benefit can be brought to the design. Based on the analysis, application of preloaded hydraulic proprietary props for deep excavations with stringent criteria would be beneficial in terms of economy and structural efficiency of the design.

\section{Correlation between pre-load force and the performance of the retaining wall}

Some research has been carried out into the correlation between prop pre-loading and the design requirements of the supported retaining wall. It is apparent that the advantage of reduced excavation-induced ground settlements by using prop pre-loads is not universally accepted within the temporary work community. This is because prop pre-load has the potential to increase unnecessarily the forces within the retaining system without offering a significant benefit. If the wall is prevented from moving, then a situation could arise where an at-rest earth pressure larger than active earth pressures is mobilised (Bond and

Table 9. Material and stiffness savings brought by the use of hydraulic props

\begin{tabular}{|c|c|c|c|c|c|}
\hline \multirow[b]{2}{*}{ City } & \multirow[b]{2}{*}{ Excavation type } & \multirow{2}{*}{$\begin{array}{l}\text { Reduction in prop stiffness per } \\
\text { metre run: }{ }^{a} \%\end{array}$} & \multicolumn{3}{|c|}{ Reduction in steel quantities } \\
\hline & & & $\begin{array}{c}\text { Steel prop } \\
\text { weight: } \mathrm{kg} / \mathrm{m}\end{array}$ & $\begin{array}{l}\text { Hydraulic prop } \\
\text { weight: } \mathrm{kg} / \mathrm{m}\end{array}$ & Difference: \% \\
\hline Dubai & Propped cantilever & 76 & \multirow{3}{*}{\multicolumn{3}{|c|}{$\begin{array}{l}\text { Steel quantities are equivalent as prop design is governed by } \\
\text { structural capacity and the required CHS is identical for the } \\
\text { conventional and hydraulic props }\end{array}$}} \\
\hline Dubai & Multipropped & $64-78$ & & & \\
\hline London & Propped cantilever & 74 & & & \\
\hline London & Multipropped & $92-95$ & 18348 & 4854 & 74 \\
\hline
\end{tabular}

a The benefits of reduced prop stiffnesses on their design are discussed in the section headed 'Benefit of lower prop stiffness for thermal effects' 
Benefits of pre-loading temporary props

for braced excavations

Latapie, Winarta and Lloyd
Harris, 2008). This may happen when using excessive pre-loads, and in extreme cases, if the magnitude of pre-loading introduced to the prop exceeds the at-rest pressures of the surrounding ground, the wall may be 'pushed back', attracting even higher ground loads than at-rest pressures.

Using values of pre-load in excess of what is required to maintain stability and minimise ground movements has the potential to induce unnecessary shear stresses and bending moments into the retaining wall. Such stress increases would in turn increase the retaining wall's reinforcement and reduce the cost-effectiveness of the overall system.

Conversely, any reduction in prop stiffness will encourage greater movement as the dig starts, leading to greater activity and reducing stresses. So in the case of pre-loaded hydraulic props, as demonstrated by the analysis results presented in this paper, the effects of reduced prop stiffness and calibrated preload force can cancel each other out as long as the pre-load is carefully selected.

This is illustrated in Figures 8 and 9, which show that the calculated change in the maximum bending moment or shear force induced into the retaining wall, from conventional steel

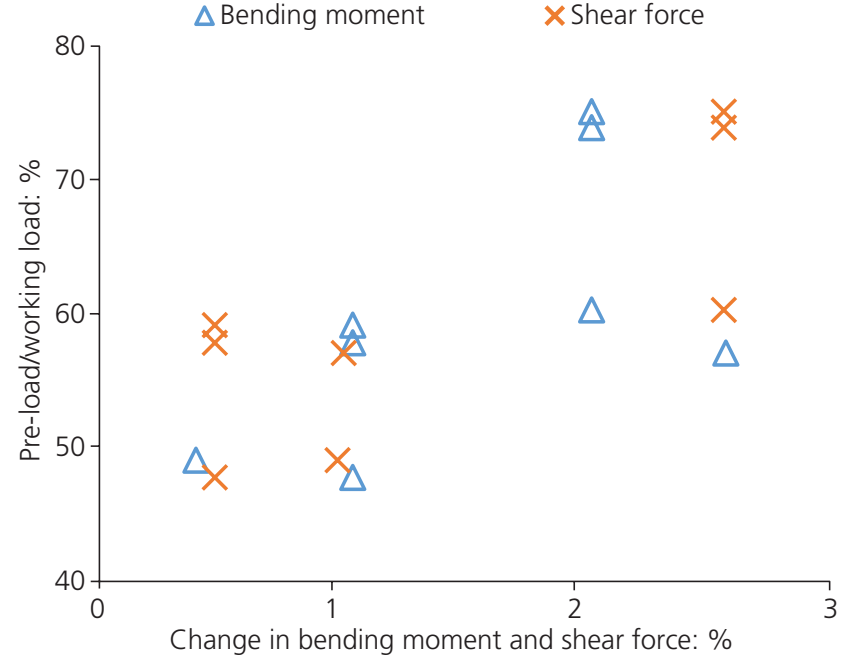

Figure 9. Comparison between ratio of applied pre-load to working load and absolute change of bending moment and shear force

props to hydraulic props with pre-load, is negligible $(<3 \%)$ for all the scenarios analysed and presented in this paper. This is also illustrated in Figure 10, which shows that the earth pressures

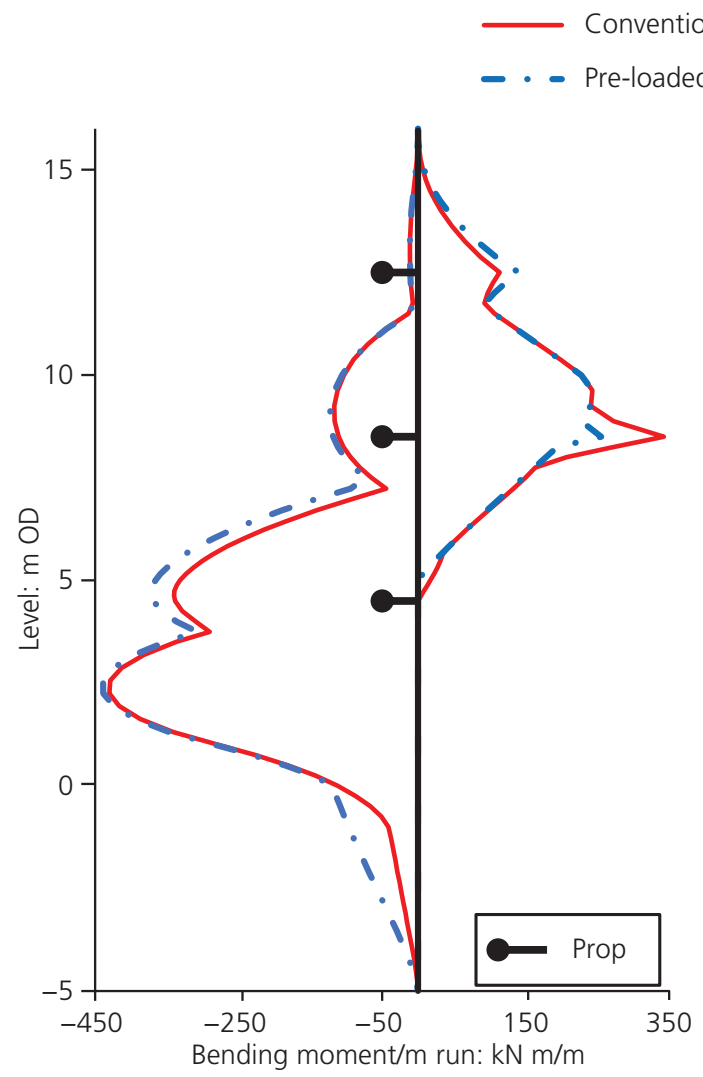

(a)

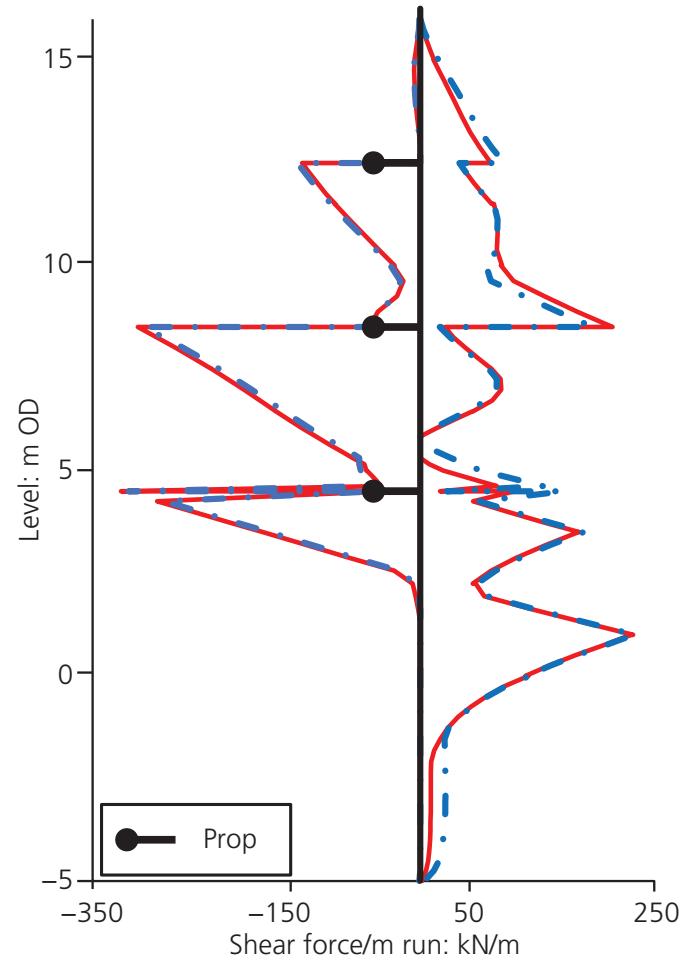

(b)

Figure 8. Comparison between (a) bending moment and (b) shear force envelope for MPL with conventional steel props and pre-loaded hydraulic props 

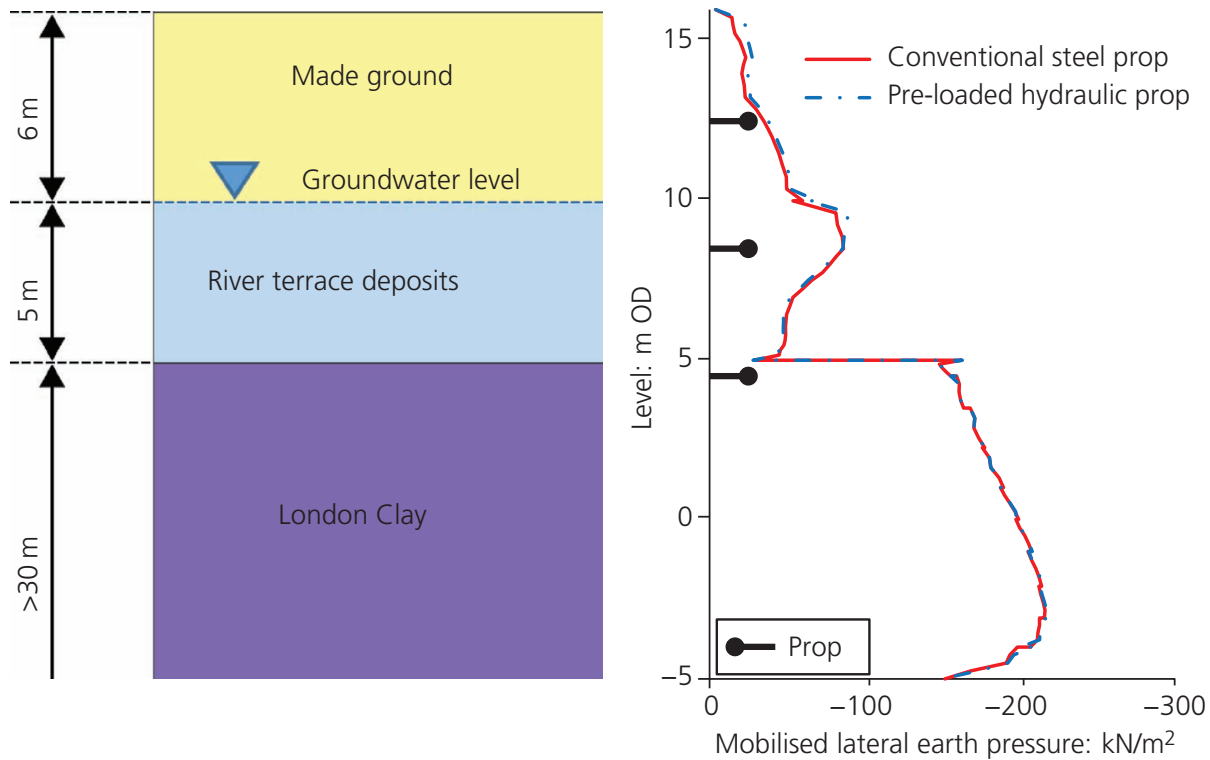

Figure 10. Plots of lateral earth pressures applied to the retaining wall for MPL

applied to the wall in the model using steel props match very well the profile from the pre-loaded hydraulic props.

The results support the authors' opinion that the use of pre-load in props, if carefully selected, can be a substitute for stiffness without having a detrimental impact on the design of the retaining wall. It is also clear that in order for efficient implementation of pre-load to be possible, the props' stiffness must also be carefully selected such that the overall support system is not made unnecessarily stiff.

When designing a retaining system, it is therefore important to ensure that the pre-load values and prop stiffnesses selected are not too high and compatible, to prevent overstressing the wall unnecessarily. The results presented in this paper suggest that preloads of $50-75 \%$ of the prop working load will achieve the required deflection criterion without increasing the structural loads or forces on the retaining wall, compared to the conventional steel prop solution, without pre-load.

\section{Benefit of lower prop stiffness for thermal effects}

As a prop heats up due to a change in ambient temperature, it will attempt to expand. Being restrained at each end by the waling beams and the retaining wall, the load in the prop will increase. The magnitude of this load will depend on the relative stiffness of the prop and the retaining wall/waling stiffness. The load variation due to temperature change is generally expressed by the following equation

7. $\Delta P_{\text {temp }}=\alpha_{\mathrm{t}} \times \Delta t \times E \times A \times \frac{\beta}{100}$

The term $\beta$ in Equation 7 is often termed the 'degree of restraint' and represents the overall stiffness of the retaining wall and waling system. Recommended $\beta$ values vary between 40 and 70 for stiff walls in stiff ground condition and between 10 and 40 for flexible walls (Twine and Roscoe, 1999).

Table 10. Material and stiffness savings brought by the use of hydraulic props

\begin{tabular}{lcccccccc} 
City & Excavation type & Prop type & Spacing: $\mathbf{m}$ & $\boldsymbol{E} \times \mathbf{A}: \mathbf{k N} / \mathbf{m}$ & $\alpha_{\mathbf{t}}:{ }^{\circ} \mathbf{C}^{-\mathbf{1}}$ & $\Delta t:{ }^{\circ} \mathbf{C}$ & $\boldsymbol{\beta}$ & $\Delta \boldsymbol{P}_{\text {temp: }} \mathbf{k N} / \mathbf{m}$ \\
\hline \multirow{2}{*}{ Dubai } & Propped cantilever & $A$ & 12 & 689700 & $1.2 \times 10^{-5}$ & 40 & 0.5 & 166 \\
& & $A_{H y d}$ & & 166935 & 12 & 40
\end{tabular}

Table 11. Material and stiffness savings brought by using hydraulic props

\begin{tabular}{|c|c|c|c|c|c|c|c|}
\hline City & Excavation type & Prop type & Spacing: $m$ & $E \times A: \mathrm{kN} / \mathrm{m}$ & Ground load: kN/m & $\Delta P_{\text {temp }}: \mathrm{kN} / \mathrm{m}$ & Total working load: kN/m \\
\hline \multirow{2}{*}{ Dubai } & \multirow{2}{*}{ Propped cantilever } & E & 4 & 2346188 & 214 & 563 & 777 \\
\hline & & $A_{H y d}$ & 10 & 200322 & 202 & 48 & 250 \\
\hline
\end{tabular}


Equation 7 shows that the load increase due to temperature is proportional to the prop's stiffness. This means that the stiffer the prop, the more thermally induced load it will attract. One of the benefits of using pre-loaded low-stiffness hydraulic props is that they will attract less thermally induced load than a stiffer steel prop of a comparable section size. This is an important consideration in the Middle East region, where design temperature gradients vary from 40 to $60^{\circ} \mathrm{C}$ with thermally induced load being a major factor in the design of temporary propping.

To demonstrate this, Equation 7 has been applied to the results of the Dubai propped cantilever scenario, with the input parameters summarised in Table 10. This shows that the conventional steel prop, due to its higher stiffness, would attract over four times more temperature-induced load than its proprietary hydraulic counterpart. All prop information in Tables 10 and 11 is presented per linear metre of retained wall in order for the results to be directly comparable.

As both struts used in the PCD scenario resulted in high utilisation ratios, they are not able to accommodate the high temperature loads typically designed for in Dubai. To determine the impact of such temperature loads onto the prop design, iterative calculations were carried out to find the additional material quantities required to accommodate those loads. This is a tedious exercise because with the temperature loads being proportional to the prop's stiffness, the larger the prop is the more load that it attracts. However, this trend is a lot gentler for hydraulic props than steel props, as they are less stiff. Prop sections and spacing were amended to find the most efficient arrangements which accommodate both the ground and temperature loads. Finite-element analyses were also recalculated to ensure that the prop forces were correctly estimated as higher support stiffnesses tend to attract higher ground loads. Outputs of this analysis are summarised in Table 11.

The conventional steel prop section had to be increased to a type $\mathrm{E}$ with the spacing reduced from 12 to $4 \mathrm{~m}$. The additional steel section required to accommodate temperature effects led to an increase in temperature loads per linear metre of excavation of $340 \%$. This means that $72 \%$ of the design load comes from temperature effects rather than ground loads. The reduced prop spacing provides a congested arrangement for a situation where ground loads are relatively small (compared to the bottom of a multipropped excavation)

In the case of the hydraulic prop, temperature loads could be accommodated by keeping the prop type with only a small adjustment of the prop spacing, down to $10 \mathrm{~m}$. This means that the temperature loads per linear metre of excavation increased only by $20 \%$ in response to this additional support stiffness. Consequently, only $19 \%$ of the design load is attributed to temperature effect, allowing a support arrangement representative of the magnitude of the ground loads to be maintained.
In both cases, the additional ground loads attracted by the higher support stiffness (per linear metre of excavation) were less than $4 \%$ and hence negligible.

\section{Conclusions and further studies}

The use of a hydraulic unit as part of a prop enables a reduction in the overall axial stiffness of the prop. In all cases analysed and presented in this paper, such stiffness reduction could be replaced by a carefully chosen pre-load. Using soil profiles typical of excavations in London and Dubai, finite-element analyses have been carried out to test the performance of steel and proprietary hydraulic temporary propping.

Numerical modelling indicates that applying a carefully chosen pre-load allows low-stiffness hydraulic props to match the performance of high-stiffness steel props, in terms of both wall deflection and induced structural shear forces and bending moments. Results for the two kinds of props considered were remarkably close to each other, which is encouraging in promoting the use of controlled pre-load with lower-stiffness props to provide an economic temporary work solution. Based on the results of the analyses presented in this paper, pre-loads of $50-75 \%$ of the prop working load achieved the required performance.

For temporary props that are governed by structural (buckling) capacity, pre-loads have been shown to have small effects on the steel section. In those cases, the main benefit of using pre-loaded proprietary hydraulic props is to reduce the prop stiffness. In situations where props are not utilised fully in their structural capacity, but governed by the deflection criterion of the retaining wall, the overall stiffness of the propping system controls the design. Hence, using pre-loaded proprietary hydraulic props allows economy on the prop steel section size and spacing as well as a reduction in the support stiffness.

The effect of thermally induced loads was discussed and estimated for one of the scenarios analysed. The use of low-stiffness props has been put forward to minimise thermal loads. It was demonstrated that using proprietary hydraulic props helps reduce the effect of thermal loads on the design of the overall retaining system. This advantage was found to have a stronger bearing on the design of support systems controlled by deflection. For locations subject to large temperature differentials, like Dubai, temperature-induced loads can govern the design of conventional steel props. Conversely, for proprietary hydraulic props, thermal loads represent a relatively small proportion of the prop's total design load.

It was proven that applying pre-load by way of a hydraulic prop can have a negligible effect on the earth pressures, bending moments and shear forces resisted by the retaining wall as long as the pre-load is carefully selected.

Further work is suggested to analyse numerically the empirical stiffness reduction factor $\beta$ for different wall types to evaluate better the thermally induced loading in the props. This is important 
Geotechnical Research

Volume 4 Issue GR3
Benefits of pre-loading temporary props

for braced excavations

Latapie, Winarta and Lloyd because the factor $\beta$ has a large impact on the proportion of thermally induced loads a propping system ought to be designed with. This would help provide a more scientific derivation of the stiffness reduction factor $\beta$, which is currently arbitrarily selected by the designer from historic observational data.

\section{REFERENCES}

Bond A and Harris A (2008) Decoding Eurocode 7. Taylor \& Francis, London, UK.

BSI (2005) BS EN 1993-1-1:2005: Eurocode 3: design of steel structures. General rules and rules for buildings. BSI, London, UK.

Burland JB, Potts DM and Walsh NM (1981) The overall stability of free and propped embedded cantilever retaining walls. Ground Engineering 14(5): $28-38$.
Chambers P, Augarde C, Reed S and Dobbins A (2016) Temporary propping at Crossrail Paddington station. Geotechnical Research 3(1): 3-16, http://dx.doi.org/10.1680/jgere.15.00009.

Gaba AR, Simpson B, Powrie W and Beadman DR (2003) C580: Embedded Retaining Walls - Guidance for Economic Design. Construction Industry Research and Information Association, London, UK.

Groundforce Shorco (2015) Technical Note 7: Design Guidance on Class 4 Circular Hollow Sections. Groundforce Shorco, Leeds, UK. See https://www.vpgroundforce.com/Groundforce/media/Groundforce/ Secured/Imported/Technical-Note-7-Guidance-on-class-4-CHS.pdf (accessed 15/06/2017).

Twine D and Roscoe H (1999) C517: Temporary Propping of Deep Excavations - Guidance on Design. Construction Industry Research and Information Association, London, UK.

\section{How can you contribute?}

To discuss this paper, please submit up to 500 words to the editor at journals@ice.org.uk. Your contribution will be forwarded to the author(s) for a reply and, if considered appropriate by the editorial board, it will be published as a discussion in a future issue of the journal. 